\title{
Firtına Deresi Alt Havzası Akım Verilerine Dayalı 1965-2015 Yılları Arası Nemli ve Kurak Dönemlerin Analizi
}

\author{
Evren TURHAN ${ }^{1 *}$, Serin DEĞERLi் $\dot{1}^{2}$
}

\section{$\ddot{\mathbf{O} z}$}

Bir havzanın uzun yıllar boyunca meydana gelen nemli ve kurak dönemleri yağışlardaki değişim ve nehir akım verilerindeki farklılıklar şeklinde kendini göstermektedir. Küresel iklim değişikliği sonucunda belirli zaman periyotlarında taşkın ve kuraklık problemleri ortaya çıkabilmektedir. Bu iki sorunun olası olumsuz etkilerini azaltabilmek adına gözlenmiş geçmiş kayıtlardan yararlanarak analizlerin yapılması ileriye dönük tahmin çalışmaları açısından doğru ve etkili bir yaklaşım sağlayacaktır. Bu çalışmada son zamanlarda mevcut su kaynaklarında debilerin azalmaya ve ciddi kuraklık etkilerinin görülmeye başladığı ifade edilen Fırtına Deresi Alt Havzası (Rize-Çamlıhemşin) uygulama alanı olarak tercih edilmiştir. Mülga Elektrik İşleri Etüd İdaresi (EİEİ)'nin 2232 nolu Akım Gözlem İstasyonu (AGİ) 19652011 ve Devlet Su İşleri (DSİ)'nin E22A067 nolu AGI'ye ait 2012-2015 yılları dataları kullanılarak Standardize Akım İndeksi (SRI) yöntemi ile 3, 6, 9 ve 12 aylık nemli ve kurak dönem değerleri elde edilmiştir. Zaman aralığ1 1965-1979, 1980-1995, 1996-2011 ve 2012-2015 yılları şeklinde dört ayrı kısımda ele alınmıştır. Çalışma sonuçlarına göre, 19652005 yılları arasında kurak dönemlerin nemli duruma göre daha yoğun yaşandığı gözlemlenirken, 2005 yılından itibaren 2013'e kadar Şiddetli ve Aşırı Nemli dönemler tespit edilmiştir. 2012-2015 yılları arasında ise kurak yıl sayılarının farklı zaman ölçekleri açısından nemli yıl sayılarına göre artış eğiliminde olması ileride kuraklığa karşı önlemlerin düşünülmesini gerektirebilecektir.

Anahtar Kelimeler: Nemli ve Kurak Dönemler, Standardize Akım İndeksi, Fırtına Deresi Alt Havzası.

\section{Analysis of Wet and Drought Periods based on Streamflow Data in the Firtına Creek Sub-basin between 1965-2015 years}

\begin{abstract}
The wet and drought periods of a basin for many years generate themselves as changes in precipitation and differences in streamflow data. Flood and drought problems may arise in certain time periods as a result of global climate change. In order to reduce the potential negative effects of these two problems, making analyzes using the observed past records will provide an accurate and effective approach in terms of future prediction works. In this study, the Firtına Creek Sub-basin (Rize-Çamlıhemşin), which has recently been pointed out to decrease on the flow rate values and noticed serious drought effects in the existing water resources, was preferred as the case study. With the Standardized Runoff Index (SRI) method, the wet and drought period values on 3, 6, 9 and 12-months have been obtained using the past data of the Flow Observation Stations (FOSs). The data belong to the Former Electrical Works Survey Administration (EIEI) with the number of 2232 for the years of 1965-2011 and the State Hydraulic Works (DSI) with the number of E22A067 for the 2012-2015 ones, respectively. The time period has been investigated in four separate sections as the years of 1965-1979, 1980-1995, 19962011 and 2012-2015. As a result of this study, it has been observed that Severe and Extremely wet periods occurred from 2005 until 2013 while the drought periods were more intense than wet conditions between 1965-2005 years. The fact that the number of drought years between 2012 and 2015 has an increasing trend compared to the wet years with regard to different time scales, can require taking precautions against the drought event in the future.
\end{abstract}

Keywords: Wet and Drought Periods, Standardized Runoff Index, the Firtına Creek Sub-basin.

\footnotetext{
${ }^{1}$ Adana Alparslan Türkeş Bilim ve Teknoloji Üniversitesi, İnşaat Mühendisliği Bölümü, Adana, Türkiye, eturhan@atu.edu.tr

${ }^{2}$ Adana Alparslan Türkeş Bilim ve Teknoloji Üniversitesi, İnşaat Mühendisliği Bölümü, Adana, Türkiye, sdegerli@atu.edu.tr
}

${ }^{1}$ https://orcid.org/0000-0002-0742-4848 ${ }^{2}$ https://orcid.org/0000-0003-0208-9152 


\section{Giriş}

Şehirleşme, nüfus yoğunluklarının artması, iklim değişiklikleri çevre üzerinde olumlu olmayan etkiler meydana getiren sebepler olarak karşımıza çıkmaktadır. Globalleşen dünyada iklim değişiklikleri hidrolojik çevrimde kuraklık, taşkın, sel,...vb. gibi doğal afetleri beraberinde getirebilmektedir (Akar ve ark., 2015). Bu afetler yıllar içerisinde değişken bir seyir oluşturabilmekte, dolayısı ile su kaynaklarının korunması ve kullanımı konusu her geçen yıl önemini biraz daha arttırmaktadır. Mevcut su kaynakları için gözlemlenmiş geçmiş veriler ile geleceğe yönelik tahmin çalışmaları su politikalarının doğru belirlenmesi yönünden ciddi katkılar ortaya çıkarabilecektir. Nehir akım veya havza yağış datalarından oluşan bir zaman periyodunda, kurak/nemli dönemlerden nemli/kurak dönemlere aralıklı olarak bir geçiş süreci yaşanabilmektedir (Şişman, 2019). Bu geçişlerin fazla olması nemlilik veya kuraklık durumunu doğrudan etkileyebilmektedir. $\mathrm{Bu}$ dönemlerin dengeli olması açısından analizlerinin yapılması su kaynakları ve sistemlerinin efektif planlanması süreçlerinde oldukça etkin bir rol oynayacaktır.

Nemlilik ve kuraklık durumlarını geçmiş yılların kayıtlarından inceleyebilmek adına birçok indisten faydalanılabilmektedir, bu indisler belirtilen süreçlerin başlangıcı ve nasıl devam ettiği konusunda nicel bir yaklaşım sağlamaktadır. Nemlilik oranı yüksek olan bölgeler su kaynakları potansiyeli açısından zengin görünmekle birlikte zaman içerisindeki tehlikeli azalmalar fark edilemeyebilir. Aslında nemli bölgeler için kuraklık, kuraklığı yaşayan yerlere göre daha ciddi tehlikeler ortaya çıkarabilir (Şen, 2015). Sadece yağış verisini giriş değerleri olarak kullanan Standart Yağış İndeksi (SPI) yöntemi McKee ve ark. (1993) tarafından geliştirilmiştir. SPI'nın pozitif tanımlı değerleri ile nemlilik, negatif olanları ile de kuraklık sınıflandırılabilmektedir (Turhan ve ark., 2016a). SPI sonuçları hem taşkın hem de kuraklık çalışmaları için sıklıkla tercih edilen metotlardandır (Tuna ve ark., 2009; Şan ve ark., 2019). Araştırma alanının Doğu Karadeniz Havzası seçildiği çalışmalarda yağış, sıcaklık ve akım verilerinin değerlendirildiği eğilim analizlerine rastlamak mümkündür (Çeribaşı ve Doğan, 2015; Akçay, 2018; Şan ve ark., 2019). Bunların yanında kuraklık indisleri üzerine yapılan trend analizi uygulamaları da mevcuttur (Partal ve Yavuz, 2020). Farklı havzalarda kuraklık indisleri yardımı ile nemli ve kurak dönemlerin ele alındığı yayınlar meteorolojik ve hidrolojik kuraklık ekseninde oluşturulmuştur. Ayrıca bitişik havzalar olan Doğu Karadeniz ve Çoruh Havzaları'nda belirlenen AGİ ve Yağış Gözlem İstasyonu (YAGİ) aylık değerleri ile yıllık bazda Kuzey Atlantik Salınımı (NAO) etkisinin sonucu olarak söz konusu parametrelerin devinimleri araştırılmıştır (Güney ve ark., 2008).

Literatür incelendiğinde Doğu Karadeniz Havzası için nemli ve kurak dönemler ile ilgili çalışmaların az sayıda olduğu görülebilmektedir. Sınırlı olan araştırma konuları genellikle eğilim analizleri şeklindedir. Partal ve Yavuz (2020) ele aldıkları çalışmalarında SPI ve De Martonne 
indislerini kullanmışlar ve Mann-Kendall testini uygulama yöntemi olarak benimsemişlerdir. Çalışmalarının bir sonucu olarak Rize, Samsun ve Çorum gibi bazı YAGI'lerde kurak ayların sayısında artış eğilimleri tespit etmişlerdir. SPI analizlerine benzer yapıda olup, Akım Kuraklık İndeksi (SDI) yöntemine göre farklı dağılım fonksiyonunu kullanan Standardize Akım İndeksi (SRI); geçmiş akım verileri ile nemli ve kurak dönemlerin sınıflandırılabildiği güncel sayılabilecek bir metot olarak uygulama alanı bulmaktadır (Shukla ve Wood, 2008; Okkan ve Altun, 2019).

Ülkemizde son yıllarda artan küresel iklim değişikliği sorunları yağış miktarının düşmesi ve sıcaklıkların normalin üzerinde seyretmesi şeklinde ortaya çıkmaktadır. Dolayısı ile yağışlar sonucu havzaya transfer olan akışın azalması hidrolojik kuraklığı açığa çıkarabilmektir. Hidrolojik kuraklığı ele alan indislerin geçmiş uzun yıllar açısından nemli ve kurak dönem sınıflandırmaları için değişimlerinin incelenmesi; projeksiyon çalışmaları için oldukça faydalı olacak, ayrıca alınacak önlemler yönünden de yol gösterici bir nitelikte olacaktır. Bu çalışmada son yıllarda debi miktarlarının önemli derecede düşüşe geçtiği belirtilen Fırtına Deresi Havzası üzerinde konumlandırılmış 2232 nolu AGİ'nin 1965-1979, 1980-1995, 1996-2011 yılları ve E22A067 nolu AGİ'nin 2012-2015 yılları arası gözlenmiş akım dataları kullanılarak 3, 6, 9 ve 12 aylık farklı zaman ölçekleri için nemlilik ve kuraklığın durumları incelenmiştir. Belirlenen sınıflandırma ölçütlerinde özellikle alt ve üst limit olan Aşırı Nemli ve Kurak dönemlerin, bunun yanı sıra da diğer orta limitlerin incelenen zaman periyotları için gerçekleştiği ay sayıları vurgulanmış, grafiklerle desteklenmiştir.

\section{Materyal ve Metot}

\section{1. Çalışma Alanı ve Akım Verileri}

Fırtına Deresi Havzası su kaynakları açısından Türkiye'nin önemli alt havzalarından biridir. Rize'nin 45 km doğusunda yer almakta ve en büyük yağış havzalarından sayılmaktadır. Su toplama alanı yaklaşık $1156 \mathrm{~km}^{2}$, dir. Havzadaki aylık toplam yağış Ocak ile Nisan ayları arası doğrusal bir şekilde düşüş göstermekte, sonrasında Ekim ayına kadar artışa geçmekte ve en son tekrar azalmaktadır. Su yılları içerisinde genellikle ilkbahar dönemi az yăğşılı veya nemli, diğer mevsimler ise çok nemli rejim hüküm sürmektedir (Yüksek ve ark., 2020). Havzada yer alan 2232 ve E22A067 nolu AGI'leri Şekil 1'de görebilmek mümkündür. 2232 nolu AGİ 1964 yılından itibaren EİEİ tarafından işletilmiş olup, en son veriler 2011 yılı için kayda alınmıştır (EİEİ, 2011). E22A067 AGİ için ise 2012-2015 yılları arası datalar bulunmaktadır (DSİ, 2015). Bu çalışmada 1965-1979, 19801995, 1996-2011 ve 2012-2015 su yılları nemli ve kurak dönemler bakımından analiz edilmiştir. 


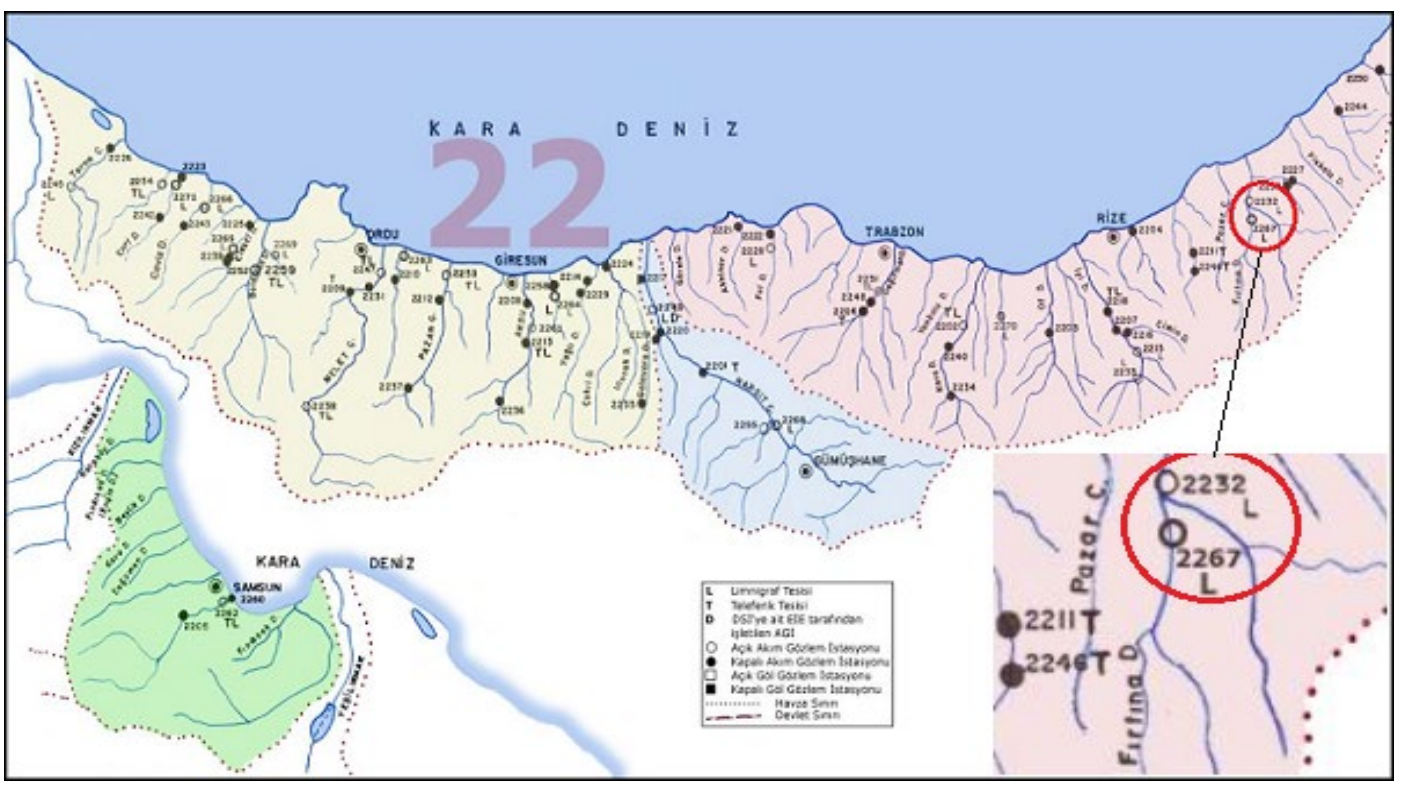

Şekil 1. Fırtına Deresi Alt Havzası AGİ konumları (EİĖ̇, 2011)

Tablo 1'de belirlenen istasyonların numaraları, adları, lokasyonları, yağış alanları ve gözlemlenmiş akım verilerinin yıllık ortalamaları gösterilmektedir (DSİ, 2015).

Tablo 1. AGİ bilgileri (DSİ, 2015)

\begin{tabular}{|c|c|c|c|c|c|c|}
\hline AGİ No & İstasyon Adı & Enlem (K) & $\begin{array}{l}\text { Boylam } \\
\text { (D) }\end{array}$ & $\begin{array}{l}\text { Yağış } \\
\text { Alanı } \\
\left(\mathbf{k m}^{2}\right) \\
\end{array}$ & $\begin{array}{c}\text { Ortalama } \\
\text { Akım } \\
\left(\mathrm{m}^{3} / \mathbf{s}\right) \\
\end{array}$ & $\begin{array}{l}\text { Değerlendirme } \\
\text { Süresi }\end{array}$ \\
\hline 2232 & $\begin{array}{l}\text { F1rtına Deresi- } \\
\text { Topluca }\end{array}$ & $41^{0} 03{ }^{\prime} 58^{\prime \prime}$ & $41^{\circ} 00^{\prime} 28^{\prime \prime}$ & 763.2 & 29.6 & \multirow{2}{*}{$\begin{array}{l}\text { 1965-2015 } \\
\text { Su Yillar1 }\end{array}$} \\
\hline E22A067 & $\begin{array}{l}\text { Hodigor Çay1- } \\
\text { Sütlüce }\end{array}$ & $41^{0} 02^{\prime} 22^{\prime \prime}$ & $41^{\circ} 00 ’ 33^{\prime \prime}$ & 504.60 & 19.68 & \\
\hline
\end{tabular}

\subsection{Standardize Akım İndeksi (SRI)}

SRI hesaplamaları farklı zaman ölçeklerinde SPI meteorolojik kuraklık değerlerinden yola çıkılarak oluşturulmaktadır (McKee ve ark., 1993). SPI yönteminde yağış verileri kullanılmakta, SDI yönteminde ise aylık ortalama akım verileri giriş parametresi olarak kabul edilmektedir (Nalbantis, 2008). SDI yönteminden farklı şekilde SRI'de akım değerlerine uygun bir dağılım hesaplanmaktadır (Pathak ve Channaveerappa, 2016). Akım verileri $\mathrm{Q}_{\mathrm{i}, \mathrm{j}}$ şeklinde gösterildiğinde $i$ hidrolojik yılı, $j$ ise Ekim ile Eylül yani su yılı içerisindeki ay sayılarını ve $k$ ise referans periyot ifadesini belirtmektedir. SDI ile kümülatif akım hacmi Denklem (1)'de olduğu gibi hesaplanabilir (Yaltı ve Aksu, 2019):

$$
\mathrm{V}_{\mathrm{i}, \mathrm{k}}=\sum_{\mathrm{j}=1}^{3 \mathrm{k}} \mathrm{Q}_{\mathrm{i}, \mathrm{j}} \quad \mathrm{i}=1,2, \ldots \quad \mathrm{j}=1,2, \ldots, 12 \quad \mathrm{k}=1,2,3,4
$$


Ekim-Aralık dönemi için k=1, Ekim-Mart dönemi için k=2, Ekim-Haziran için k=3 ve EkimEylül için k=4 olarak öngörülmektedir. Kümülatif akım hacimlerine göre $i$ hidrolojik yılın her bir $k$ ifadesi için SDI değeri aşağıdaki şekilde oluşturulmaktadır (Denklem (2)):

$$
S D I_{\mathrm{i}, \mathrm{k}}=\frac{\mathrm{V}_{\mathrm{i}, \mathrm{k}}-\overline{\mathrm{V}_{\mathrm{k}}}}{\mathrm{S}_{\mathrm{k}}}, \mathrm{k}=1,2,3,4
$$

Denklem (2)'deki $V_{k}$ ve $S_{k}$ kümülatif akım hacimlerinin ortalamasını ve standart sapma değerini tanımlamaktadır. SRI; Shukla ve Wood (2008) tarafından nehir akım verilerini dikkate alarak nemli ve kurak dönemleri inceleyebilmek amacıyla geliştirilmiştir. Datalar uygun bir olasılık dağılımı ile ifade edilmektedir (Pathak ve Channaveerappa, 2016). Akarsu akım verileri gibi değişken yapıdaki giriş parametreleri normal dağılımdan daha çok iki parametreli Gamma dağılımına uyum sağlamakta, dolayısı ile de yöntemin ele alınmasında bir düzenleme gerekli görülmektedir (Okkan ve Altun, 2019). Akım verilerinden faydalanılarak 3, 6, 9 ve 12 ay için SRI değerleri hesaplanmıştır. Bu değerler Aşırı Nemli ve Aşırı Kurak arasında sekiz değişik sınıflandırmaya bölünmüştür. Tablo 2'de SRI alt ve üst limit değerlerinin sınıflandırılmış hali görülebilmektedir (Turhan ve ark., 2016b; Turhan ve ark., 2019):

Tablo 2. SRI sinıflandirması (Turhan ve ark., 2019)

\begin{tabular}{ll}
\hline SRI Değeri & Sınıflandırma \\
\hline SRI $\leq-2$ & Aşırı Kurak (AK) \\
$-2<$ SRI $\leq-1.5$ & Şiddetli Kurak (ŞK) \\
$-1.5<$ SRI $\leq-1$ & Orta Kurak (OK) \\
$-1<$ SRI $\leq 0$ & Hafif Kurak (HF) \\
$0<$ SRI $\leq 1$ & Hafif Nemli (HN) \\
$1<$ SRI $\leq 1.5$ & Orta Nemli (ON) \\
$1.5<$ SRI $\leq 2$ & Şiddetli Nemli (ŞN) \\
SRI $>2$ & Aşı1rı Nemli (AN) \\
\hline
\end{tabular}

\section{Bulgular ve Tartışma}

Müteferrik Doğu Karadeniz Suları Havzası’nda yer alan 2232 numaralı Fırtına Deresi- Topluca ve E22A067 nolu Hodigor Çayı-Sütlüce istasyonlarında 3, 6, 9 ve 12 aylık çeşitli zaman ölçekleri için SRI değerlerinin zamansal dağılımı Şekil 2'de belirtilmiştir. Hesaplanan SRI-3 değerlerine bakıldığında 1968, 1987, 1990, 1993, 2006 ve 2011 yıllarında Aşırı Nemli durum gözlemlenirken; 1967, 1969, 1983, 1985 ve 1997 yıllarında ise Aşırı Kurak dönemlerin meydana geldiği dikkat çekmektedir. SRI-6 grafiğinde Aşırı Kurak dönem sadece 1965-1979 yılları arasında oluşurken, tüm 
yıllar göz önüne alındığında Şiddetli Kuraklığın olduğu zamanlar da ayrıca göze çarpmaktadır, buna ek olarak SRI-6'da 1968, 1990 ve 1993 yıllarında Aşırı Nemli dönem tespit edilmiştir.

\section{SRI-3}

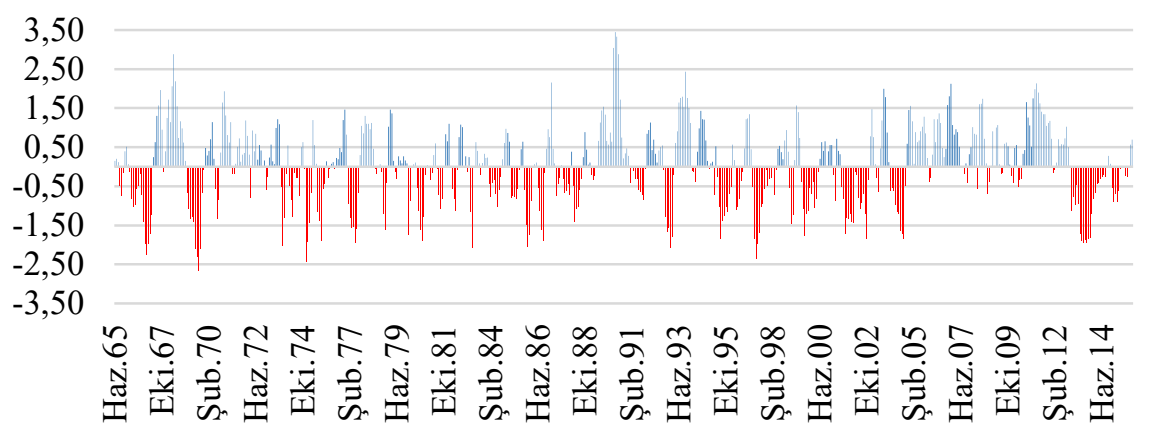

SRI-6

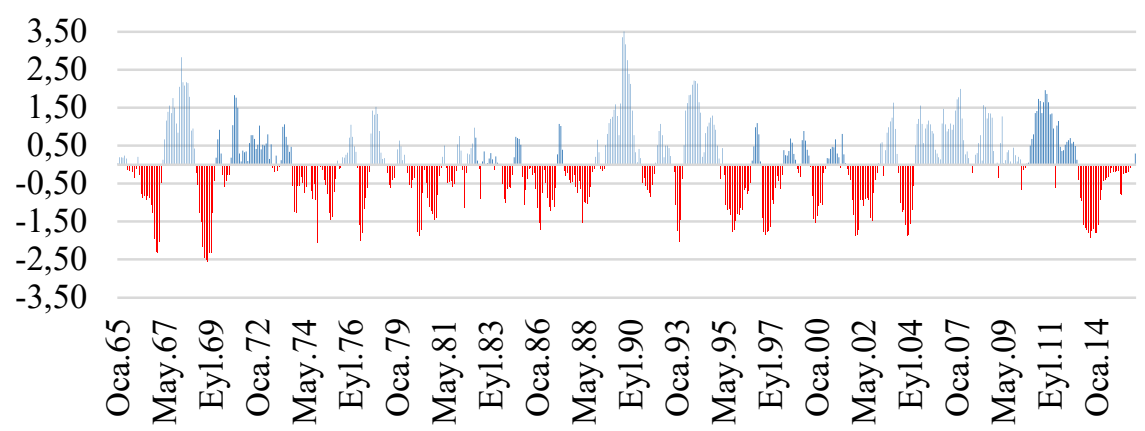

SRI-9

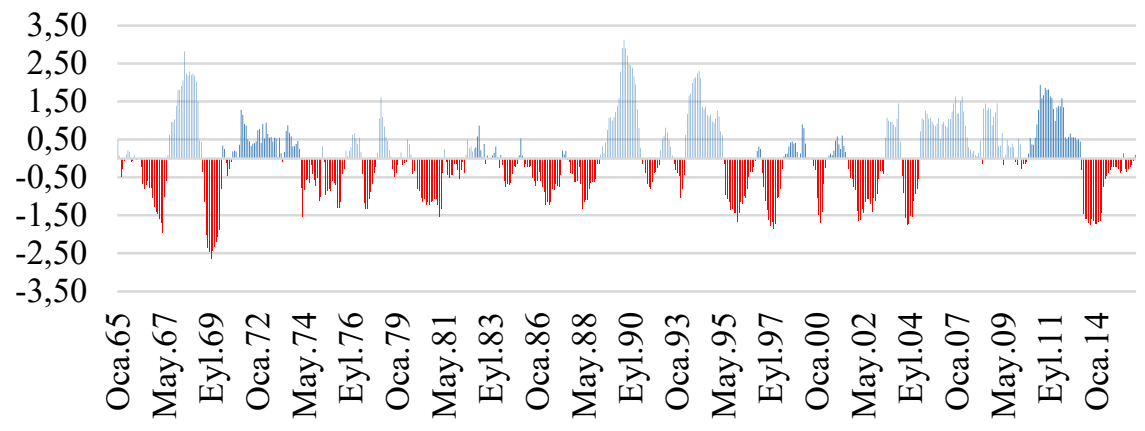

SRI-12

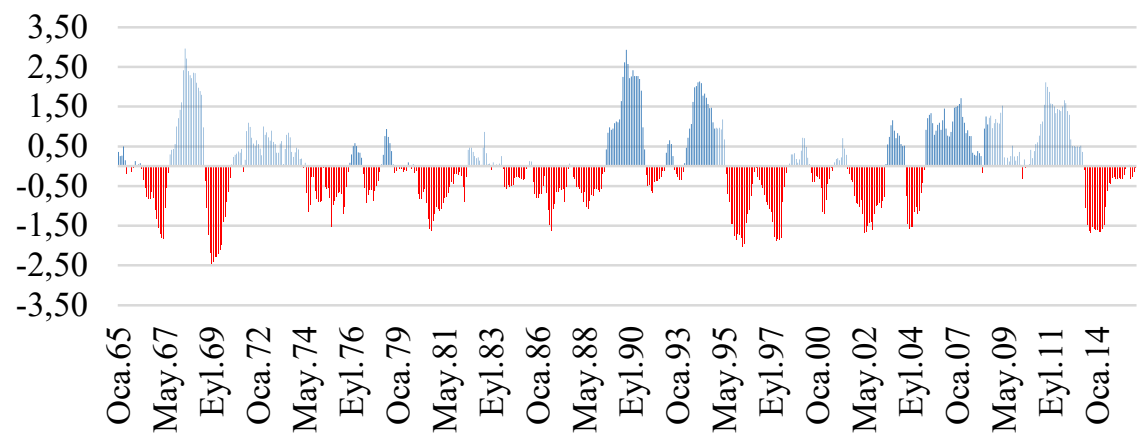

Şekil 2. SRI ölçeklerinin zamansal değişimi 
SRI-9 grafiğinde Ocak 1969 dönemi ele alınan tüm yıllar boyunca hesaplanan tek Aşırı Kurak durum olarak izlenmiştir. 1968, 1990 ve 1993 yıllarında ise Aşırı Nemli durum meydana gelmiştir. SRI-12 grafiğinde 1969 ve 1996 dönemlerinde Aşırı Kurak durum belirlenirken; 1968, 1990, 1993 ve 2012 yıllarında Aşırı Nemli dönemler görülmektedir. 3, 6, 9 ve 12 aylık dönemlerin ortalama değerleri üzerinden farklı zaman ölçeklerinde hesaplanan SRI değerleri Şekil 3 'te verilmektedir.

SRI 3 (Ekim)

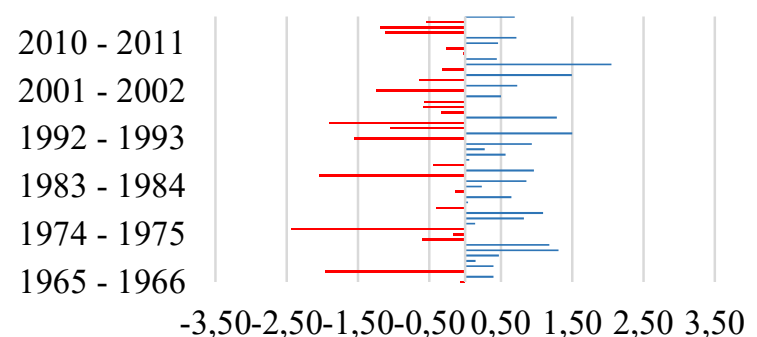

SRI 3 (Ocak)

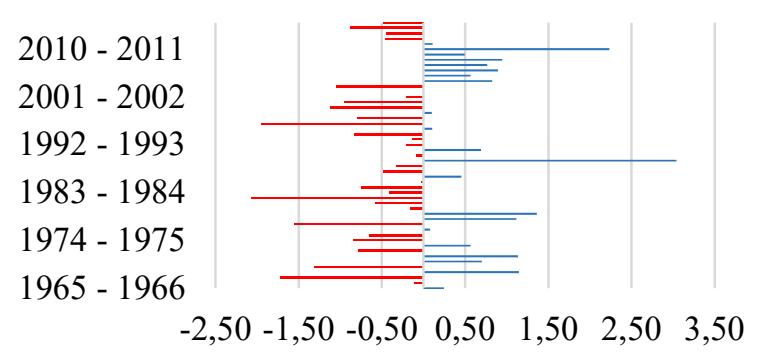

SRI 6 (Ekim)

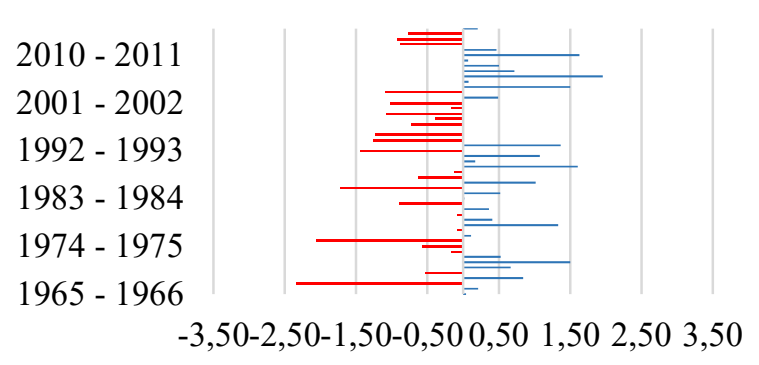

SRI 9

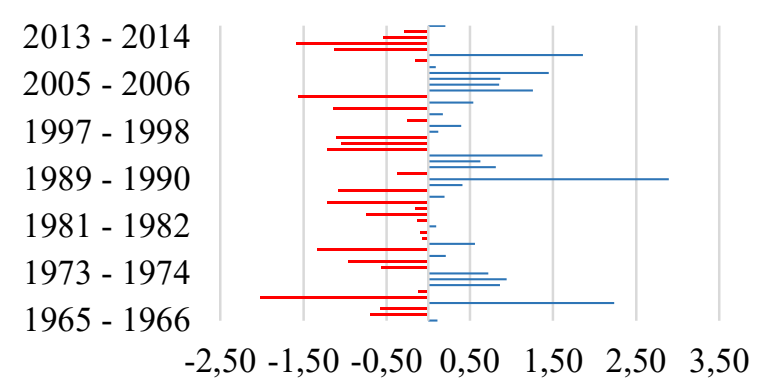

SRI 3 (Nisan)

$2010-2011$
$2001-2002$
$1992-1993$
$1983-1984$
$1974-1975$
$1965-1966$

$-2,50-1,50-0,50 \quad 0,50 \quad 1,50 \quad 2,50 \quad 3,50$

SRI 3 (Temmuz)

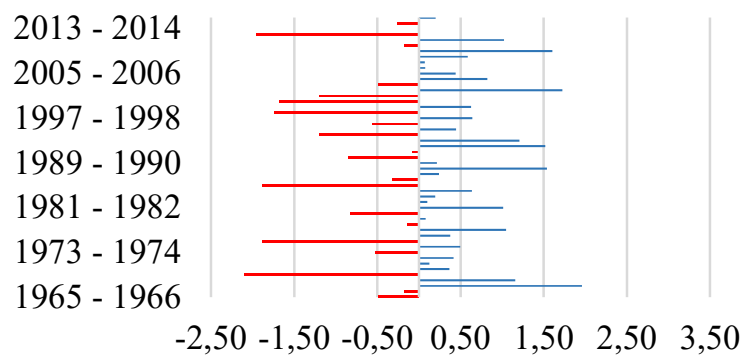

SRI 6 (Nisan)

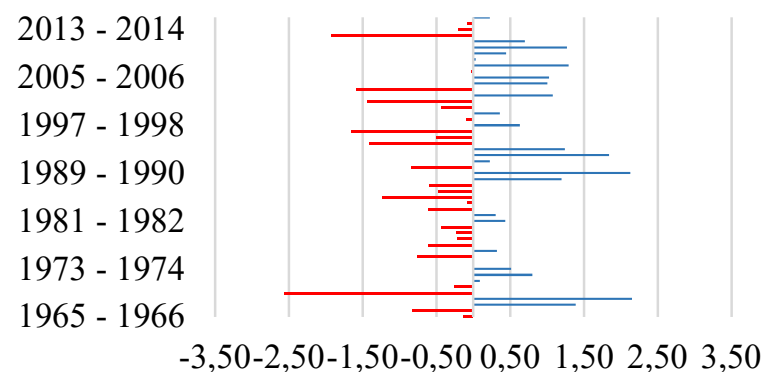

SRI 12

$2013-2014$

$2005-2006$

$1997-1998$

$1989-1990$

$1981-1982$

$1973-1974$

$1965-1966$

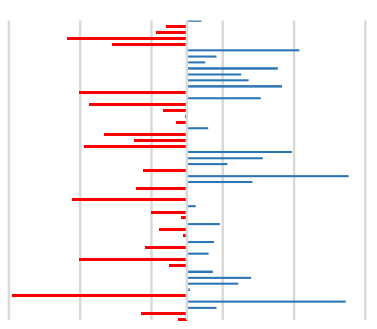

$-3,50-2,50-1,50-0,500,501,502,503,50$

Şekil 3. SRI-3, 6 ,9, 12 su yıllarına göre değişim grafiği 
Tüm zaman dilimlerine bakıldığında 2005 yılının başından 2013 yılına kadar Şiddetli ve Aşırı Nemli dönemler dikkat çekmektedir. 1965-2005 yılları arasında kuraklığın nemliliğe göre daha yoğun yaşandığı gözlemlenirken, 2005-2013 yılları arasında Hafif Kuraklık sınıflandırması üzerinde kuraklıklara pek rastlanmamıştır. Genelde nemliliğin yoğun olarak görüldüğü yıllar 1968 ve 1990 şeklinde, kuraklığın en yoğun görüldüğü dönem ise 1969 ve 1996 yılları olarak ifade edilebilir. Partal ve Yavuz (2020) çalışmalarında; Doğu Karadeniz Bölgesi'ndeki tüm istasyonları değerlendirdiklerinde SPI indisine göre 1960 ile 2015 yılları arası için Nemlilik sınıflandırmalarında artış eğilimi tespit etmişlerdir.

Ekim, Kasım ve Aralık aylarının SRI değerleri ortalama alınarak SRI-3 (Ekim) şeklinde gösterilmekte ve bu grafik üzerinde değerlendirme yapılırsa 1985 yılında Aşırı Kurak, 1992 ve 1995 yıllarında ise Şiddetli Kurak durum gözlemlenmiştir. Ayrıca 2006 yılında Aşırı Nemli, 1993 yılında ise Şiddetli Nemli dönem tespit edilmiştir. Ocak, Şubat, Mart aylarının ortalamasıyla bulunan SRI-3 (Ocak) periyodu içerisinde 1982 yılında Aşırı Kurak dönem oluşmuş, 1989 ve 2011 yıllarında Aşırı Nemli durum meydana gelmiştir. Nisan, Mayıs ve Haziran ayları için hesaplanan SRI-3 (Nisan) grafiğinde 1996 ve 2003 yıllarında Şiddetli Kuraklık dikkat çekerken, herhangi bir Aşırı Kurak dönem belirlenmemiş, 1989 yılında ise Aşırı Nemli dönem tespit edilmiştir. SRI-3 (Temmuz) döneminde ise Aşırı Kurak veya Nemli durum ortaya çıkmamış, ancak 1985, 1998 ve 2000 yıllarında Şiddetli Kuraklık etkili olmuş; 1988, 1992, 2002 ve 2009 yıllarında Şiddetli Nemli dönemler ortaya çıkmıştır.

Bir su yılını iki dönemde inceleyen SRI-6 (Ekim) ve SRI-6 (Nisan) grafiklerinde Aşırı Kurak durum gözlenmemiş olup, SRI-6 (Ekim) değerlerinde 1985 yılı itibari ile Şiddetli Kuraklık meydana gelmiştir. SRI-6 (Nisan) periyodunda Aşırı Nemli durum 1990 yılında elde edilmiştir. SRI-9 ve SRI12 grafiklerinde 1990 yılı içerisinde Aşırı Nemli durum gözlenirken; 2003 yılında ise Şiddetli Kuraklık tespit edilmiştir. Bu zaman periyodu için herhangi bir Aşırı Kurak durum gözlenmemiştir. Tüm zaman ölçekleri birlikte incelendiğinde 1990 yılı nemliliğin, 1996 yılı ise kuraklığın en yoğun görüldüğü dönemler olarak ifade edilebilir.

Kurak ve nemli dönemlerin geçmiş yıllardan günümüze kadar sayılarının tüm ölçekler için belirlenmesi amacı ile 1965-1979, 1980-1995, 1996-2011 ve 2012-2015 yıllarını kapsayan dört ayrı dönem incelenmiş ve sonuçları Tablo 3'te verilmiştir. Kuraklık sayılarının değişimi analiz edildiğinde; 1965-1979 dönemi ile 1996-2011 yıllarının birbirine yakın sayılarda olduğu gözlenmiştir. İlk 15 yıllık dönemden sonraki kuraklık sayılarında ve nemli yıllarda da bir artış görülmüştür ancak kurak dönem sayılarındaki artışın nemli yıllara kıyasla daha fazla olduğu belirlenmiştir. Daha sonraları her bir SRI periyodu için kuraklık sayılarında azalma gözlemlenmiş, bununla birlikte nemlilik sayılarında daha yüksek bir artış meydana gelmiştir. Nemlilik sayısının 1965-2011 zaman aralığı boyunca artarak devam ettiği tespit edilmiştir. Ancak son zamanlarda 
yaşanan küresel iklim değişikliği sebebiyle akım verilerinde azalan yönde trendlerin olması beklenmektedir (Çeribaşı ve Doğan, 2015). Tüm periyotlar açısından SRI değerlerinin 0.5 'ten küçük olması Kurak dönemi, 0.5 'ten büyük olması Nemli dönemi, -0.5 ile 0.5 aralığ ise Normal dönemi göstermektedir. Bu doğrultuda Şekil 4’teki grafikler elde edilmiştir.

Tablo 3. Belirlenen zaman aralıkları için Kuraklık ve Nemlilik sayıları

\begin{tabular}{ccccc|cccc} 
& \multicolumn{4}{c}{ Kuraklık Sayıları } & \multicolumn{4}{c}{ Nemlilik Sayıları } \\
\cline { 2 - 9 } & $S R I-3$ & $S R I-6$ & $S R I-9$ & $S R I-12$ & $S R I-3$ & $S R I-6$ & $S R I-9$ & $S R I-12$ \\
\hline $\mathbf{1 9 6 5 - 1 9 7 9}$ & 50 & 51 & 53 & 57 & 53 & 49 & 48 & 47 \\
\hline $\mathbf{1 9 8 0 - 1 9 9 5}$ & 58 & 59 & 64 & 65 & 54 & 54 & 50 & 49 \\
\hline $\mathbf{1 9 9 6 - 2 0 1 1}$ & 52 & 50 & 51 & 56 & 76 & 68 & 67 & 68 \\
\hline $\mathbf{2 0 1 2 - 2 0 1 5}$ & 19 & 15 & 14 & 14 & 9 & 15 & 13 & 12 \\
\hline
\end{tabular}
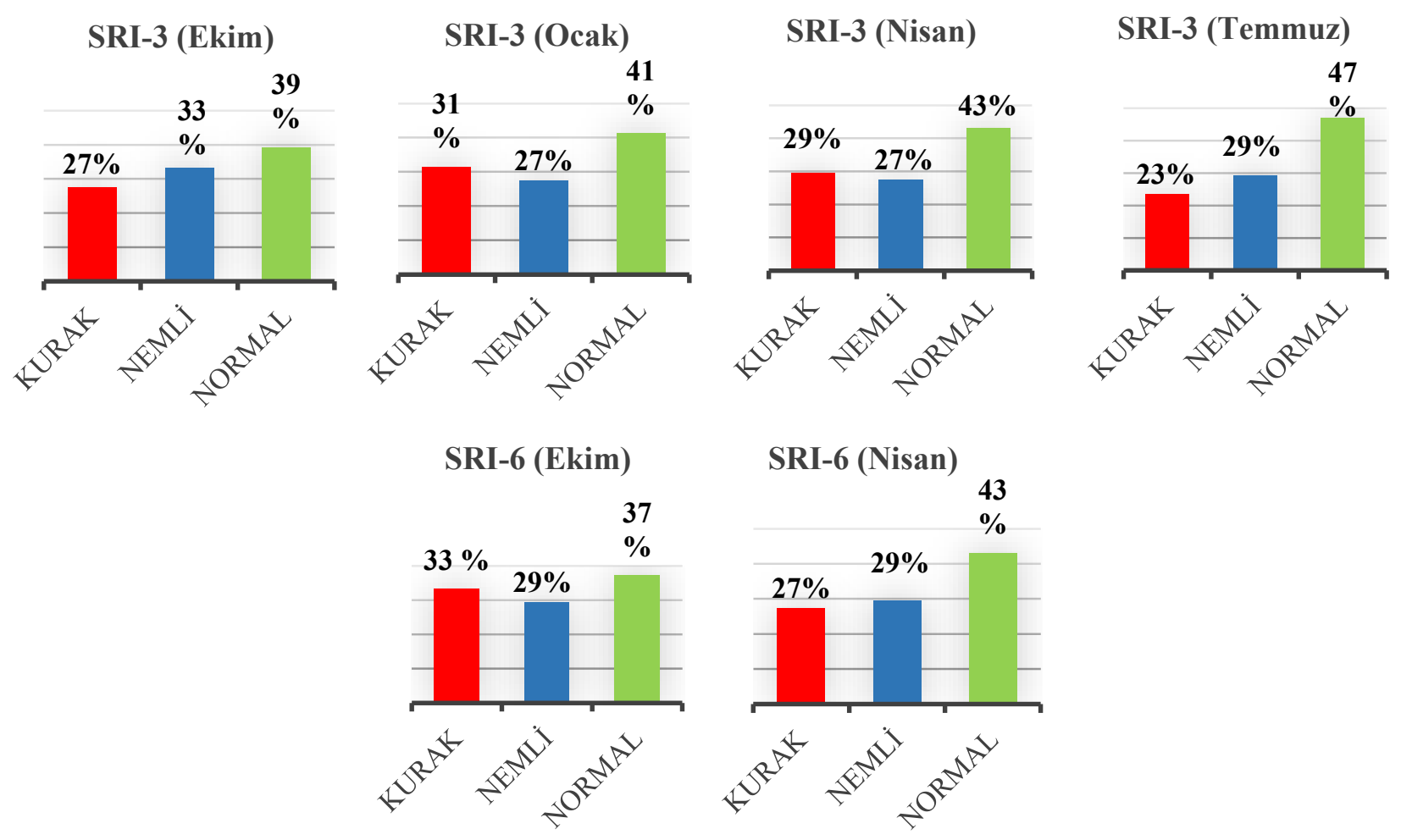

SRI-6 (Nisan)

SRI-9
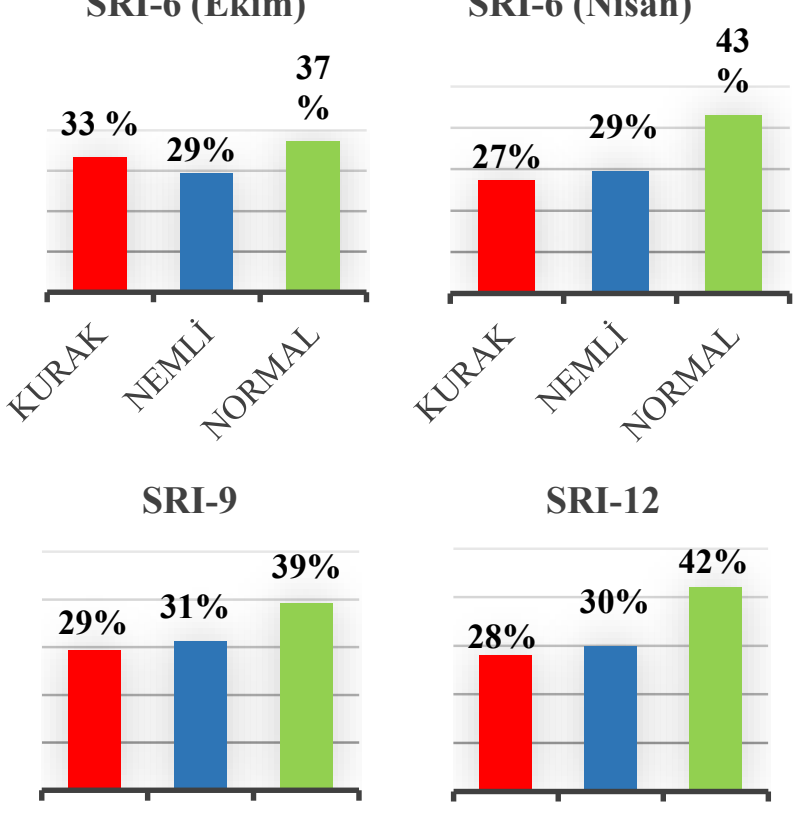

SRI-12
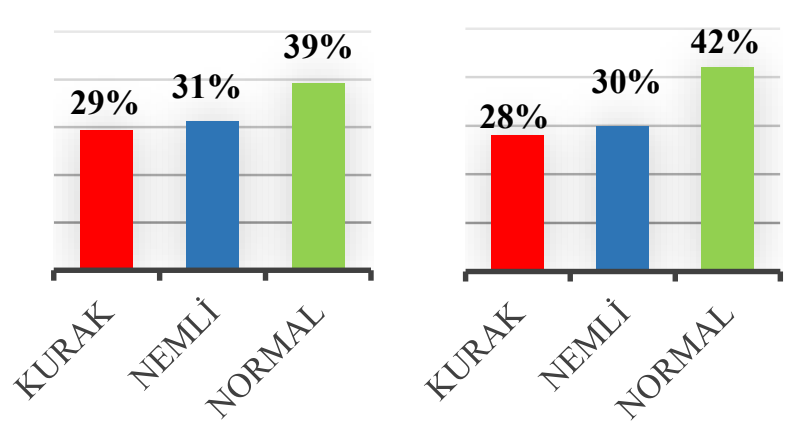

Şekil 4. Havzada AGI'’lerin SRI değerlerine göre dağılım yüzdeleri (\%) 
SRI-3 (Temmuz) grafiğindeki değerler en düşük seviyeli akım verilerine sahip dönem ile hesaplanmasına rağmen nemli durum yaklaşık \%29, kurak durum ise \%23 olarak elde edilmiştir. SRI3 (Ocak) grafiğinde kurak dönem \%31 ile nemli koşullara göre az bir farkla daha yüksek çıkmıştır. SRI-6 (Ekim)'de nemliliğin meydana gelme oranı \%29 bulunurken, kuraklık \%33 seviyelerinde gözlemlenmiştir. SRI-9'da nemli ve kurak dönem değerleri sırasıyla yaklaşık \%31 ve \%29'dur. SRI12'de nemli dönem \%30, kurak dönem ise \%28 dolaylarında hesaplanmıştır. SRI değerleri için genel anlamda -0.5 ile 0.5 arasında yer alan normal dönemlerin daha sıklıkla gözlendiği söylenebilir. Buna ek olarak göz önüne alınan yılların çoğunda akım değerlerinin daha yüksek olduğu dönemleri içeren SRI-3 (Ocak) ve SRI-6 (Ekim) grafiklerinde kuraklığın daha fazla, buna karşın akım değerlerinin daha düşük seviyelerde görüldüğü dönemleri kapsayan SRI-3 (Temmuz) ve SRI-6 (Nisan) değerlerinde ise nemlilik sayısının daha fazla olduğu tespit edilmiştir. Bu koşullar yağış, kar erimesi, buharlaşma gibi hidrolojik parametrelerin etkisi ile değişkenlik gösterebilmektedir.

\section{Sonuçlar ve Öneriler}

Global iklim değişikliği sonucu taşkın ve kuraklık gibi doğal afetlerin görülme sıklığı artmaya başlamıştır. Bu sorunların olumsuz etkilerini ortadan kaldırabilmek için geçmiş gözlem verilerinden faydalanılarak analizlerin yapılması tahmin çalışmaları için ciddi katkılar sunabilecektir. $\mathrm{Bu}$ çalışmada son yıllarda debi miktarlarının önemli derecede azaldığı belirtilen Fırtına Deresi Havzası üzerinde konumlandırılmış 2232 nolu AGİ'nin 1965-1979, 1980-1995, 1996-2011 yıllar ve E22A067 nolu AGİ'nin 2012-2015 yıllar gözlenmiş akım verileri kullanılarak 3, 6, 9 ve 12 aylık farklı zaman ölçekleri için nemlilik ve kuraklığın durumları araştırılmaya çalışılmıştır. Belirlenen sınıflandırma ölçütlerinde özellikle alt ve üst limit olan Aşırı Nemli ve Kurak dönemlerin, bunun yanı sıra da diğer orta limitlerin incelenen zaman periyotları için gerçekleştiği sayılar vurgulanmış, grafiklerle açiklanmıştır.

Çalışma sonucunda geçmişte ele alınan birçok su yılı açısından Aşırı Nemli ve Aşırı Kurak dönemlerin yaşandığı görülebilmektedir. SRI-3 zaman ölçeği için 1968-2011 yılları arasında yer yer Aşırı Nemlilik gözlemlenirken, 1967-1997 yılları arası Aşırı Kurak döneme denk gelmiştir. SRI-6 düşünüldüğünde sadece 1965-1979 yılları arası Aşırı Kurak seyretmiş, 1968-1993 yılları arasında ise çok seyrek Aşırı Nemli periyot fark edilmiştir. SRI-9 ve SRI-12'de Aşırı Nemli dönem sayıları kurak döneme nazaran daha fazladır. 2005-2013 yılları arası kuraklık daha nadir gözlenmiştir. SRI değerleri için genel anlamda -0.5 ile 0.5 sınır koşulları göz önüne alındığında normal dönemlerin daha çoğunlukta olduğu ifade edilebilir. Akım debilerinin daha fazla olduğu dönemleri içeren SRI-3 (Ocak) ve SRI-6 (Ekim)'de kuraklığın daha yüksek, aksine akım değerlerinin daha az seviyelerde olduğu periyotları kapsayan SRI-3 (Temmuz) ve SRI-6 (Nisan)'da nemli ay sayılarının daha fazla 
olduğu görülebilmektedir. 2012-2015 gibi kısa zaman aralığı söz konusu olsa dahi son zamanlarda nemliliğe göre kurak dönemlerin sayısında artış görülebilmektedir. Şen (2015)'in ifade ettiği şekilde nemli bölgeler için kuraklık durumunun, kuraklığı yaşayan yerlere göre daha ciddi tehlikeler oluşturabileceği değerlendirildiğinde ileriki dönemlerde olası problemlerin baş gösterme ihtimali bulunmaktadır. Dolayısıyla farklı akım indeksleri ile yapılabilecek çalışmalar ve gelecekteki tahminleri ele alacak modellemeler önlemler noktasında 1şık tutabilecek bilgiler sağlayabilecektir.

\section{Yazarların Katkısı}

Tüm yazarlar çalışmaya eşit katkıda bulunmuştur.

\section{Çıkar Çatışması Beyanı}

Yazarlar arasında herhangi bir çıkar çatışması bulunmamaktadır.

\section{Araştırma ve Yayın Etiği Beyanı}

Yapılan çalışmada araştırma ve yayın etiğine uyulmuştur.

\section{Kaynaklar}

Akar, Ö., Oğuz, İ., Yürekli, K. (2015). İkikara Havzası'nın kurak ve ıslak dönemlerinin bazı kuraklık indisleri yardımıyla karşılaştırılması. Gaziosmanpaşa Üniversitesi Ziraat Fakültesi Dergisi, 32(2), 7-13.

Akçay, F., (2018). Doğu Karadeniz Havzası aylık ve yıllık ortalama akımlarının eğilim (trend) analizi. Yüksek Lisans Tezi, Karadeniz Teknik Üniversitesi Fen Bilimleri Enstitüsü, Trabzon.

Çeribaşı, G., ve Doğan, E., (2015). Trend analizi yöntemi kullanılarak Batı ve Doğu Karadeniz ile Sakarya Havzası akım miktarlarının değerlendirilmesi. SDU International Technologic Science, 7(2), 1-12.

Devlet Su İşleri (DSI), (2015). Akım gözlem yıllıkları (1959-2015), Ankara.

Elektrik İşleri Etüd İdaresi (EIEİ). Akım gözlem yıllıkları (1935-2011), Ankara.

Güney, Ş.C., Akyüz, İ., ve Yılmaz, M.F., (2008, Ağustos). Doğu Karadeniz ve Çoruh Havzalarının hidrolojik verilerinde Kuzey Atlantik salınımının sinyallerinin aranması. Taşkın, Heyelan ve Dere Yataklarının Korunmast Konferansi, DSI, Trabzon.

McKee, T. B., Doesken, N. J., ve Kleist, J., (1993). The relationship of drought frequency and duration to time scales. 8th Conference on Applied Climatology, Am. Meteorol. Soc. Boston, 179-184.

Nalbantis, I., (2008). Evaluation of a hydrological drought index. European Water, 23/24: 67-77.

Okkan, U., ve Altun, H., (2019, Kasım). Susurluk Havzası akımlarının hidrolojik kuraklık analizinde Standardize Akım İndeksi ve paylaştırılmış entropi yöntemlerinin kıyaslanması. 4th International Symposium on Innovative Approaches in Engineering and Natural Sciences, SETSCI Conference Proceedings, Samsun, 4(6), 329-335.

Partal, T., ve Yavuz, E., (2020). Batı Karadeniz bölgesinde kuraklık indisleri üzerine trend analizi uygulanmas1. Doğal Afetler ve Çevre Dergisi, 6(2): 345-353, http://dx.doi.org/10.21324/dacd.643161

Pathak, A. A., ve Channaveerappa, B.M.D., (2016). Comparison of two hydrological drought indices. Perspectives in Science, 8, 626-628. 
Shukla, S., ve Wood, A.W., (2008). Use of a Standardized Runoff Index for characterizing hydrologic drought. Geophys. Res. Lett., 35.

Şan, M., Kankal, M., Bayram, A., ve Nacar, S., (2019, Haziran). Doğu Karadeniz Havzası'nda yağış ve kuraklığın eğilim analizi. ISTE-CE'2019- International Conference on Innovation, Sustainability, Technology and Education in Civil Engineering, İskenderun, Hatay, 670-681.

Şen, Z., (2015). Preface, In Z. Şen (Ed.), Applied Drought Modeling, Prediction, and Mitigation, Boston: Elsevier, 9-11.

Şişman, E., (2019). Su talep seviyesine göre kurak veya sulak dönem analizi. Dicle Üniversitesi Mühendislik Fakültesi (DÜMF) Mühendislik Dergisi, 10(1), 301-310.

Tuna, H., Malkoç, F., ve Yılmaz, Ö., (2009, Kasım). Çoruh Havzası'nda SPİ ile kuraklık analizi ve çevresel etkileri. Doğu Karadeniz Bölgesi Hidroelektrik Enerji Potansiyeli ve Bunun Ülke Enerji Politikalarındaki Yeri, Forum, Trabzon, 114-129.

Turhan, E., Özmen-Çağatay, H., ve Çetin, A., (2016a). Yapay sinir ağı yöntemleri ile Aşağı Seyhan Ovası Alt Havzası yağış-akış ilişkisinin modellenmesi ve yağışl1-kurak dönemler açısından irdelenmesi. Çukurova Üniversitesi Mühendislik Mimarlık Fakültesi Dergisi, 31(2), 227-241.

Turhan, E., Özdil, N.F., Tantekin, A., (2016b, Ekim). Hidrolojik kuraklık ve enerji verimliliği ilişkisinin pompaj depolamalı hidroelektrik santraller (PDHES) konusu bağlamında değerlendirilmesi: Adana örneği. International Energy\&Engineering Conference, UEMK Proceedings, Gaziantep, 143-158.

Turhan, E., Keleş, M.K., Tantekin, A. ve Keleş, A.E., (2019). The investigation of the applicability of datadriven techniques in hydrological modeling: The case of Seyhan Basin. Rocznik Ochrona Srodowiska, 21, 29-51.

Yalt1, S., ve Aksu, H., (2019). Drought analysis of Iğdır Turkey. Turkish Journal of Agriculture-Food Science and Technology, 7(12): 2227-2232, http://dx.doi.org/10.24925/turjaf.v7i12.2227-2232.3004

Yüksek, T., Özçelik, A.E., ve Verep, B., (2020). Fırtına Havzası'nın bazı havza karakteristikleri ile arazilerin fizyografik özelliklere göre dağılımlarının coğrafi bilgi sistemleri ile belirlenmesi. Anadolu Çevre ve Hayvancilı Bilimleri Dergisi, 5(3), 439-449. 